\title{
Class Reservation Application
}

\author{
Rikip Ginanjar*, Alvin Halim \\ President University \\ *Corresponding author: rikipginanjar@president.ac.id
}

\begin{abstract}
Many student do class reservation for their own problem in the class either the lecturer or the student itself that do the reservation. In president university class reservation become one of the important system that exist in the university organization system to service of unanticipated extra schedule for the sake of class session. No wonder in one day so many student do the class reservation but wasting time because of complicated process of the reservation and also manual process that annoying especially for student. The university have computerized system for everything process in the university but not this simple one yet important. Many student always wasting time for only booking one class room that disturbing their activity because of the manual paper administration. The academic still use paper and find manually when they want to search empty room or checking room of some lecturer, because of this there happen so many times of miss information and communication that caused by negligance of the staff. We cannot hope them to do everything perfect because human can do some wrong too because of imperfectness that is why we need another solution for this to solve the problem.
\end{abstract}

\section{INTRODUCTION}

Many mis-information happen when President University academic bureau serving the lending class facilities. People always get a lot trouble doing this only for get one room for use. In this university this facility become primary uses by the the student also the lecturer. Many people use this facility for their own concern and depend to this but the service cannot satisfied the user enough because the lack of the system.

Manual process of this facility is the most big reason the delay and how bad this service is caused. This also make the process sequence long only for rent a room. that is only matter of rent room but the bureau doesn't only serve this matter but also another people objective related to the academic come to solve their matters. This show how bad the process is because the miss match to the current situation.

This program is also a continue one of class task when studying in the university to get a bachelor. Rather that this project abandoned, it better continue to the greater project and than before in a class
Student took long sequence to get one room for use because of the manual writing paper process that student have must apply to get a class or room. This unfit condition system to the current situation make so many mis-information especially during the process and more over the academic still use manual note to write schedule and remembering all reserved room. This method that cause the big trouble of mis-information in the academic to the student and lecturer.

This project should help to solve the room reservation problem of the university that happen many times of miss communication and miss information when lending of some room and complicated process of the administration.

Because of the process of room reserving manually the system will use current technology of application program designed special for this only current situation. For now the project will use web programming language as the builder of the prototype. The explaination as below.

\section{Scope}

The system will designed and build for persentation purpose only of this research script which mean anything transcript on this script might be changed due to further development of the project in the possibility future. The system will not capable implemented to real time because the project purpose only for persentation and need further analysis of the real condition. Because of that, the development will use rapid method process that will explain further in the next section.

\section{MethodOLOGY}

The Rapid Application Development (RAD) is the correct method to use on this time because of the short time available to build the prototype. Not only fast but also more simple to do it alone and easier. This is the simple way to develop a prototype during the short time. The cycle looped over and over again in the section of building the prototype. It require amount of time to create oonly one prototype. It process again, again and again back to coding and building the program until it reach the requirement or objective of the project for the research. At least it capable to present the everything overall of all the point of this research and it's real objective. 
It is this method is bad for building a program because no specific documentation during process of buidling the program because you do everything fast and no time for documentation because of the narrow of time of this project. Documentation become less and loss information of how the program built. But, aside that it fast process and result.

The method is lost of documentation but it doesn't mean do not have advantages with this method way. The advantages is as described as below.

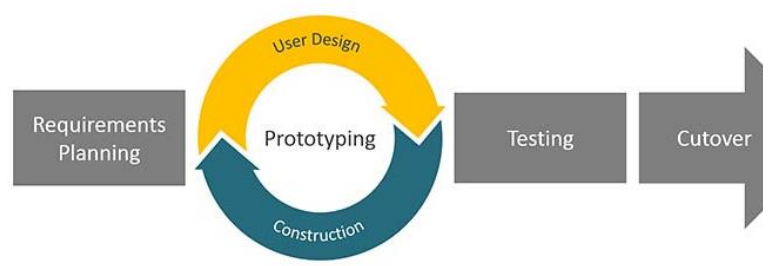

Figure 1 Rapid Application Development (RAD)

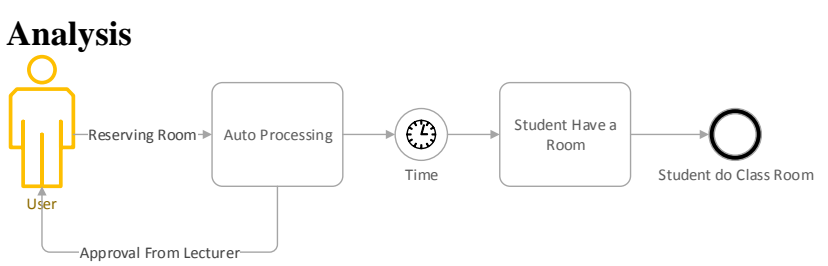

Figure 2 Overall View System

The purpose Class Resevation Application (CRAp) a system that solve the problem of room reserving automatically without complicated and long process. The application must be easy to use by user and auto generate the information without a chance of miss and wrong information. The chance of lost and wrong data must be as lowest rate as possible to avoid information loss. This chance of lost data can be cause by many thing included of fail system work flow or program failure and the human self. Because of that the system must be carefully special designed to have not chance lead to failure process that could harm the data and cause information lost. This kind of problem must be avoided to not cause failure system that only lead to another new problem or maybe even worse. Further analysis and explaination is on the next this paragraph. 
IT FOR SOCIETY, Vol. 03, No. 02

ISSN 2503-2224

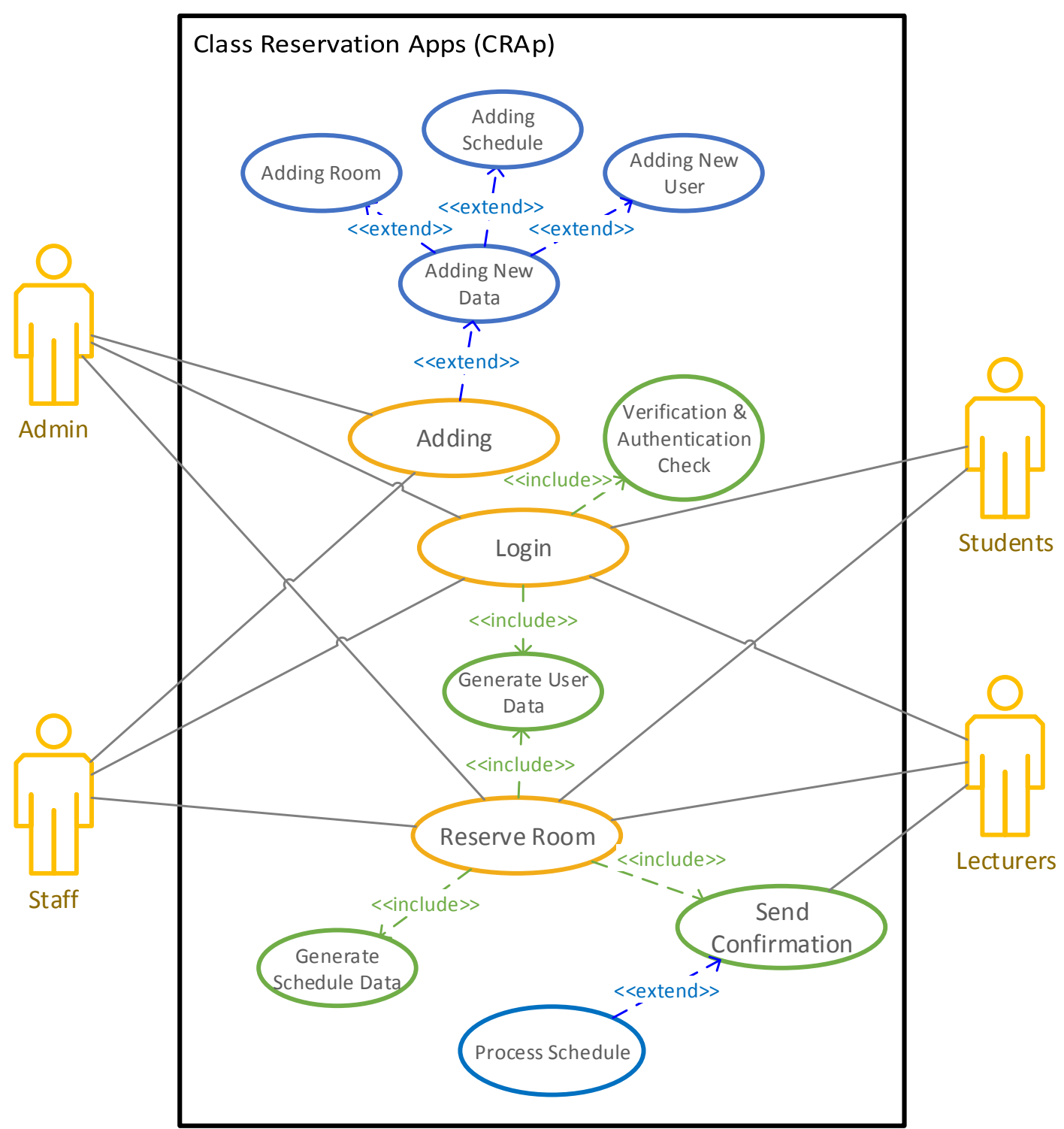

Figure 3 The overview of the designed system

The system will have two type of user in term of authorities of each individual. It doesn't mean all of them have same authorities for each category. All of the user have their own authorities depends on who they are and what their position in the university. below is the explaination of the user.

\section{a) Login}

User will face a login interface at first time acessing the system. User must enter their own account from login interface form to access further into the system. System will verified the account and authorization of the user and will show the system feature base the role in the university. Higher position have high access into the system, the system only need check the authority of the user and give the access to the system further more than the other.
The log in system will not have only one method to access into the system. System can use UID card method to give alternative login for the user by using their ID card of the university. user will only need tap their card to the prepared device and they can enter the system instantly without username or password. This alternative can expand more to the system not only for login.

After user $\log$ in to the system, user will can access to the system feature denpend on their access authority such as reserving room, system configuration (authority and user setting), adding calendar, new room, new user, class schedule, data extraction, and logout.

\section{b) Reserving Room}

The interface will show calendar of the schedule for the whole month and week to the user to give information of the available time and room for adding new schedule to the 
academic curriculum. All schedule of the whole month in periodic year is able to see from here including holiday, normal schedule, and national holiday. But not specific information shown on the interface.

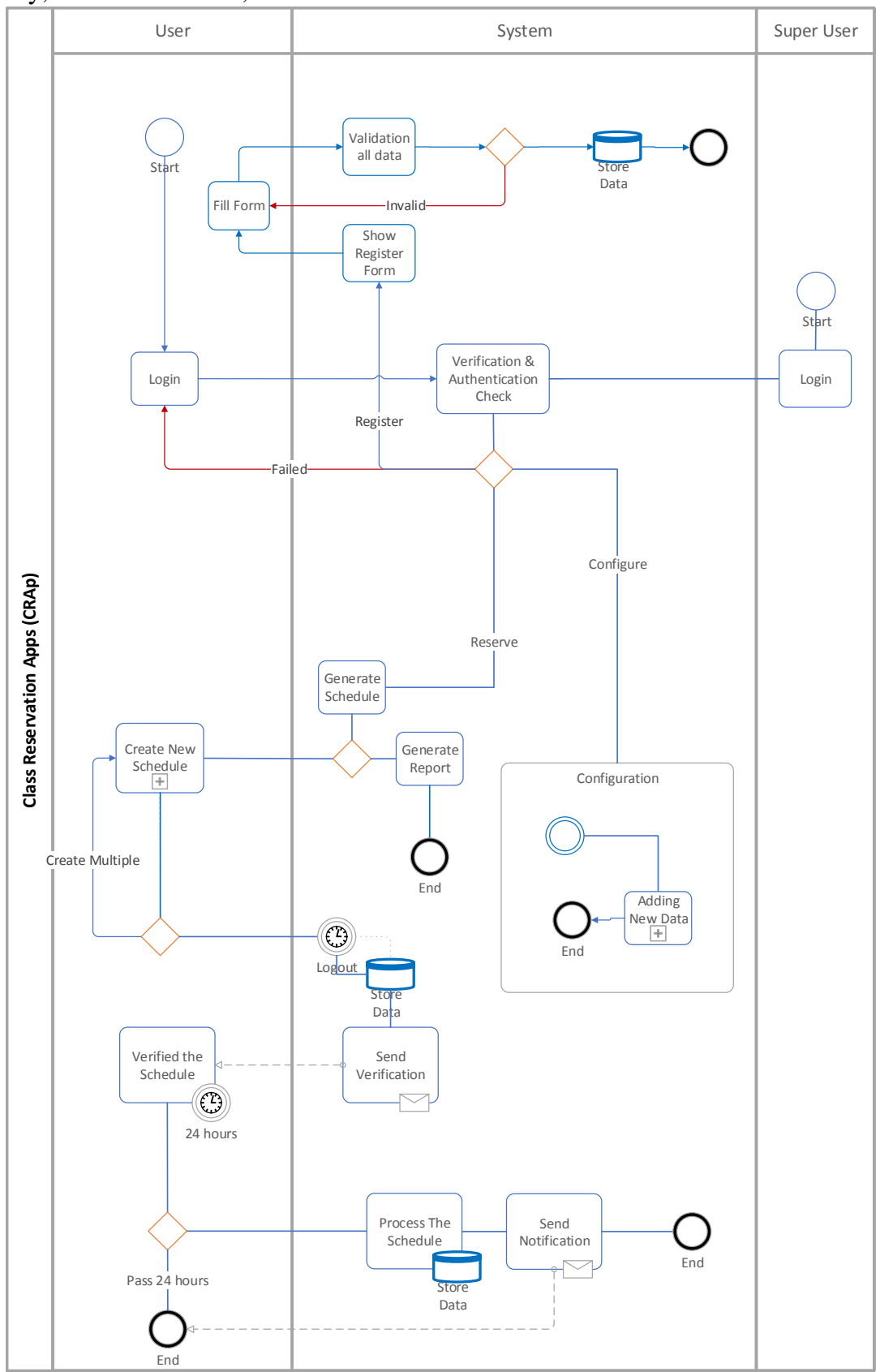

Figure 4 Overall View Work Flow BPMN Class Reservation System 
IT FOR SOCIETY, Vol. 03, No. 02

ISSN 2503-2224

\section{CONCLUSION}

The system automation reservation that purposed to solve problem of manual reservation working good. From the system development seems look like have benefits compare the existed current system. The developed system need further development to adapt the real situation. The result will described as below.

1. The automation system system have more advantage rather than the manual reservation.

2. Base on testing of the system it work perfectly from generating the dates, status indicator, and update database also reserving the new make up classes.

3. The system able to add new room without disturbing the existed database into error. Everything turn out to be integrated.

4. User can adding new user by a simple authorized system and only staffs can do that.

5. Calendar change and marked correctly.

6. Database inserting and update work correctly fine.

\section{References}

[1] Patel, Nikunj. 5 Key Benefits of Using Rapid Prototyping for Product Design \& Development. Medical Design Technology. [Online] MDT, 06 March 2015. [Dikutip: 1 May 2017.] https://www.mdtmag.com.

[2] Anonymous. Web Development. Wikipedia. [Online] April 16, 2017. https://en.wikipedia.org/wiki/Web_developme nt.

[3] -. MySQL. Wikipedia. [Online] Wikipedia, 28 April 2017. [Dikutip: 1 May 2017.] https://en.wikipedia.org/wiki/MySQL.

[4] Data, Refsnes. w3schools. w3schools. [Online] Refsnes Data, 1 January 1999. [Dikutip: $20 \quad$ April 2017.] https://www.w3schools.com.

[5] Page, Larry dan Brin, Sergey. Google. Google. [Online] Google, 4 September 1998. [Dikutip: $\quad 1 \quad$ April 2017.] https://www.google.com/.

[6] Easy to Use Javascript Calendar. $D H X$. [Online] DHTMLX, 11 2017. [Dikutip: 95 2017.] https://dhtmlx.com. 